\title{
Notas Sobre a História dos Serviços de Educação Especial em Manaus, Amazonas ${ }^{1}$
}

\author{
Notes on the History of Special Education Services in Manaus, Amazonas
}

Notas sobre la Historia de los Servicios de Educación Especial en Manaus, Amazonas

\author{
Samuel Vinente \\ Universidade Federal de São Carlos (Brasil) \\ http://orcid.org/0000-0002-7205-9680 \\ http://lattes.cnpq.br/9897424792722413 \\ samueljunior.ns@gmail.com \\ Márcia Duarte Galvani \\ Universidade Federal de São Carlos (Brasil) \\ https://orcid.org/0000-0003-1092-746X \\ http://lattes.cnpq.br/6866106661255961 \\ marciaduar@yahoo.com.br
}

\section{Resumo}

Os estudos sobre a configuração dos serviços especializados vêm ganhando cada vez mais força na literatura científica. Entretanto, ainda carecemos de estudos que auxiliem na compreensão da organização dessa política em diferentes contextos, bem como o resgate dos aspectos históricos de constituição desses serviços. O presente estudo objetivou descrever e analisar o histórico da oferta dos serviços de Educação Especial em Manaus entre 1892 e 2016. Trata-se de uma pesquisa documental realizada em materiais publicados no Diário Oficial Municipal do Município e no sítio eletrônico do Conselho Municipal de Educação. Foi realizado um levantamento em teses e dissertações que tiveram a capital amazonense como objeto de estudo, além dos sítios eletrônicos de instituições especializadas, órgãos públicos e blogs locais. Os resultados apontaram para o pioneirismo da atuação de instituições especializadas, bem como as formas organizativas do trabalho pedagógico na perspectiva clínica, que aos poucos foram redimensionando-se para a perspectiva pedagógica.

Palavras-Chaves: Educação Especial. História da Educação. Manaus.

\footnotetext{
${ }^{1}$ Os autores agradecem ao apoio do Conselho Nacional de Desenvolvimento Científico e Tecnológico (CNPq) e da Fundação de Amparo à Pesquisa no Estado do Amazonas (FAPEAM).
} 


\begin{abstract}
Studies on the configuration of specialized services have been gaining strength in the scientific literature. However, we still lack studies that help in understanding the organization of this policy in different contexts, as well as the recovery of the historical aspects of constitution of these services. The present study aimed to describe and analyze the history of the provision of Special Education services in Manaus between 1892 and 2016. This is a documentary research carried out on materials published in the Municipal Official Gazette of the Municipality and on the electronic website of the Municipal Council of Education. A survey was carried out on theses and dissertations that had the Amazonian capital as object of study, besides the electronic sites of specialized institutions, public agencies and local blogs. The results pointed to the pioneering practice of specialized institutions, as well as the organizational forms of pedagogical work from a clinical perspective, which were gradually re-dimensioned into the pedagogical perspective.
\end{abstract}

Keywords: Special Education. History of Education. Manaus.

\title{
Resumen
}

Los estudios sobre la configuración de los servicios especializados vienen ganando cada vez más fuerza en la literatura científica. Sin embargo, todavía carecemos de estudios que ayuden en la comprensión de la organización de esa política en diferentes contextos, así como el rescate de los aspectos históricos de constitución de esos servicios. El presente estudio objetivó describir y analizar el histórico de la oferta de los servicios de Educación Especial en Manaus entre 1892 y 2016. Se trata de una investigación documental realizada en materiales publicados en el Diario Oficial Municipal del Municipio y en el sitio electrónico del Consejo Municipal de Educación. Se realizó un levantamiento en tesis y disertaciones que tuvieron la capital amazonense como objeto de estudio, además de los sitios electrónicos de instituciones especializadas, organismos públicos y blogs locales. Los resultados apuntaron al pionerismo de la actuación de instituciones especializadas, así como las formas organizativas del trabajo pedagógico en la perspectiva clínica, que poco a poco fueron redimensionando hacia la perspectiva pedagógica.

Palabras Claves: Educación Especial. Historia de la Educación. Manaus. 


\section{Introdução}

No Brasil Colônia as pessoas com deficiência eram recolhidas pelas Santas Casas de Misericórdia, juntamente com os doentes e as crianças abandonadas. Esse recolhimento teve início no ano de 1543 em Santos (SP), iniciativa essa denominada de Roda dos Expostos (MAZZOTTA, 2005; FIGUEIRA, 2011; JANNUZZI; CAIADO, 2013).

A Roda dos Expostos funcionou no Brasil entre 1726 e 1950, como uma medida assistencial de acolhimento, baseada em um sistema de proteção à criança abandonada. As formas desse atendimento seguiam a tradição portuguesa e foram implantadas em Salvador (1726), no Rio de Janeiro (1738), em Recife (1789) e São Paulo (1825) (FIGUEIRA, 2011).

No contexto educacional, o marco temporal da Educação Especial foi a criação do Instituto dos Meninos Cegos (1854) e do Instituto dos Surdos-Mudos (1856), ambos como iniciativa do Poder Público. Enquanto iniciativa privada, foi em 1926, que houve a fundação do Instituto Pestalozzi (MAZZOTTA, 2005; MENDES, 2010; FIGUEIRA, 2011).

No contexto do atendimento às pessoas com deficiência se objetivou a oferta de tratamento médico e alívio da sobrecarga familiar e social, ficando a educação desse público reduzida à iniciativa da área médica e às instituições religiosas e filantrópicas (PESSOTTI, 1984). Esperava-se que as práticas educativas especiais curassem as deficiências, gerando comportamentos normalizados (PESSOTTI, 1984; MENDES, 2006).

A normalização nada mais foi que a defesa do princípio de que o deficiente pudesse dispor de condições de vida mais próximas de pessoas comuns (OMOTE, 1999). Esse princípio consolidou no contexto brasileiro ações governamentais que implementaram o ideário da integração sob o argumento de que "[...] todas as crianças com deficiências teriam o direito inalienável de participar de todos os programas e atividades cotidianas que eram acessíveis para as demais crianças" (MENDES, 2006, p. 388).

O descaso do Poder Público e a escassez de serviços de Educação Especial na década de 1950 potencializaram o surgimento de movimentos comunitários que se organizaram e implantaram redes de escolas especiais privadas filantrópicas (JANNUZZI, 2004; MENDES, 2006, 2010). Dessa forma, em 1954 foi fundada a primeira Associação de Pais e Amigos dos Excepcionais (APAE) no Rio de Janeiro, bem como o primeiro serviço de atendimento educacional especializado para pessoas com superdotação (JANNUZZI, 2004; BRASIL, 2008; MENDES, 2010; JANUZZI; CAIADO, 2013).

Em 1961, a Lei $\mathrm{n}^{\circ}$ 4.024/1961 apresentou em seus artigos 88 e 89, as diretrizes para a educação dos excepcionais. Segundo essa lei, no que fosse possível, a educação dos excepcionais deveria enquadrar-se no sistema geral de educação, fomentando a integração desses estudantes na comunidade. O artigo 89 possibilitou também o financiamento do Poder Público a qualquer iniciativa privada considerada eficiente pelos conselhos estaduais de educação. Tal financiamento poderia ocorrer mediante concessão de bolsas de estudo, empréstimos e subvenções (BRASIL, 1961).

Para Mazzotta (2005) estava posta na legislação “[...] a mesma e velha questão da destinação das verbas públicas para a educação, comum ou especial, agravada pela indefinição da natureza do atendimento educacional" (MAZZOTTA, 2005, p. 69). Considerando então a ausência de atuação do Estado na formulação de políticas públicas para essa população pode-se observar a proliferação de instituições que passaram a ofertar os serviços especializados.

Após a publicação da Lei $n^{\circ} 4.024 / 1961$ foi possível observar o crescimento das instituições privadas de cunho filantrópico. Segundo Mendes (2010), o fortalecimento da iniciativa privada se deveu primeiramente a uma omissão do Estado, que forçou uma mobilização comunitária que preenchesse a lacuna do sistema escolar brasileiro. Um dos exemplos refere-se ao fato de que em 1962 haviam apenas 16 instituições filiadas à APAE. Atualmente, conforme dados da Federação Nacionais das APAES, o quantitativo de 
instituições vinculadas é de mais de duas mil, atendendo a um público de aproximadamente 250 mil pessoas (FENAPAES, 2018).

O debate sobre o delineamento dos serviços de Educação Especial se deu principalmente com a utilização dos termos Segregação, Integração, Inclusão. A partir da década de 1960, passou a ser conveniente adotar a ideologia da integração, pela economia que ela poderia representar aos cofres públicos, tendo em vista que os gastos com os serviços de Educação Especial com caráter de segregação eram muito elevados (MENDES, 2006).

O início da institucionalização ocorreu simultaneamente com o auge do discurso da normalização. Discurso esse que, para Rech (2010), busca a padronização do indivíduo, possibilitando que os diferentes se tornem parecidos com o modelo ideal de cidadão. Mais tarde, a filosofia da institucionalização foi substituída na década de 1990 pelo movimento da inclusão escolar.

Segundo Omote (1999), o termo inclusão apresenta avanços em relação à normalização e à integração. Ao passo em que as instituições especializadas também reproduzem as exclusões que ocorrem na sociedade, a manutenção delas poderia contribuir com o "convívio e socialização para os deficientes que, em função do grave comprometimento, não têm possibilidade de frequentar recursos de Educação Especial da rede regular de ensino" (p. 7). A Política Nacional de Educação Especial na Perspectiva da Educação Inclusiva (BRASIL, 2008), preceitua a inclusão enquanto "paradigma educacional fundamentado na concepção de direitos humanos que conjuga igualdade e diferença como valores indissociáveis [...]" (p. 1).

Considerando então essa discussão pode-se observar inúmeros estudos no contexto amazonense que foram debruçando-se sobre os aspectos históricos, políticos e educacionais dos serviços especializados no município de Manaus. Vinente e Matos (2014), ao mapearem a produção científica do Programa de Pós-Graduação em Educação (PPGE) da UFAM entre 1988 e 2012 verificaram que, de um total de 349 trabalhos, 30 referiam-se a temática de Educação Especial.

Em relação às pessoas com deficiência que residem no estado do Amazonas, Barros (2014) chama atenção para o fato de que o conhecimento sobre a realidade dessas pessoas na região Amazônica não evidenciava um quantitativo preciso, nem o perfil (tipo de deficiência) ou distribuição dessa população. A ausência de pesquisas que se debruçassem sobre esses aspectos contribuiu para a invisibilidade dessa população na sociedade, e consequentemente, exclusão dos seus direitos fundamentais enquanto pessoa humana (BARROS, 2014).

Embora haja uma tendência de pesquisas sobre a oferta dos serviços de Atendimento Educacional Especializado (AEE) na capital amazonense (MATOS, 2008; MARQUES, 2010; SANTOS, 2011; VINENTE, 2017). Poucos estudos têm se debruçado a narrar a história desses serviços, de modo a contextualizar os aspectos nacionais da política com a conjuntura local. Nesse sentido, o presente estudo objetivou descrever e analisar o histórico da oferta dos serviços de Educação Especial em Manaus entre 1892 e 2016.

\section{Método}

\section{Delineamento}

Esse estudo trata-se de uma pesquisa documental, a qual segundo Gil (2008), vale-se de materiais que ainda não receberam um tratamento analítico, podendo ainda ser reelaborados de acordo com os objetivos da pesquisa. Segundo Fonseca (2002), esse tipo de pesquisa recorre a fontes diversificadas e dispersas, sem tratamento analítico, tais como tabelas, estatísticas, jornais, revistas, relatórios, documentos oficiais, entre outros. 


\section{Período}

O período compreendido nas fases de seleção e análise dos materiais foi baseado entre os anos de 1892, data do primeiro registro de matrícula de estudantes com deficiência no Unidade Educacional Euclides de Cunha, e 2016, data da publicação da Resolução no 011/2016/CME, que institui novos procedimentos e orientações para Educação Especial, na perspectiva da Educação Inclusiva, no Sistema Municipal de Ensino de Manaus.

\section{Definição das Fontes de Pesquisa}

As fontes de pesquisa utilizadas nesse estudo basearam-se em: (a) publicações do Diário Oficial do Município de Manaus e do Conselho Municipal de Educação (CME); (b) documentos dispostos nas teses e dissertações publicadas pelo Programa de PósGraduação em Educação (PPGE) da Universidade Federal do Amazonas (UFAM); (c) documentos e registros publicados em blogs locais, sítios eletrônicos de instituições especializadas e órgãos públicos.

\section{Procedimentos de Coleta dos Dados}

Para a coleta dos materiais documentais realizou-se uma pesquisa junto aos sítios eletrônicos do Conselho Municipal de Educação e do Diário Oficial do Município de Manaus, buscando identificar as publicações que diziam respeito aos serviços de Educação Especial. Após esse procedimento foram selecionados os documentos que instituíram a modalidade de Educação Especial (MANAUS, 1991), normatizaram os serviços especializados (MANAUS, 2003, 1998, 2011, 2016) e criaram escolas e centros especiais (MANAUS, 1998, 2007).

Em relação às teses e dissertações foi realizado o contato inicial junto à Coordenação do PPGE/UFAM para anuência da instituição visando a realização do presente estudo. Após isso foram identificadas no âmbito do Programa as publicações que versavam sobre o tema. Após o refinamento dessas publicações foram selecionados os trabalhos que apresentavam em sua estrutura, anexos ou apêndices, documentos que responderiam aos objetivos do estudo (LIMA, 1992; SANTOS, 1998; OLIVEIRA, 2007; CORRÊA, 2013; BATISTA, 2015).

Em relação aos blogs locais e sítios eletrônicos das instituições especializadas do município de Manaus realizou-se primeiramente o mapeamento das instituições mais antigas. Posteriormente foram realizadas buscas nos sítios eletrônicos dessas instituições visando obter documentos e informações sobre o histórico dos serviços especializados ofertados. No caso de algumas instituições que não possuíam site próprio, a busca foi realizada em blogs locais e regionais.

\section{Procedimentos de Análise dos Dados}

Os materiais obtidos foram lidos e organizados sistematicamente para compor o quadro de análise dos dados. Tal análise foi fundamentada com base no aporte teórico de Bordgan e Biklen (1994). Os materiais foram catalogados, quantificados e agrupados por ordem cronológica. Após a distribuição por categorias, os dados foram reagrupados sistematizados a partir dos seguintes itens: (a) atuação das instituições especializadas; (b) as ações governamentais; e, (c) os tipos de serviços ofertados. 


\section{Resultados e Discussões}

\section{Atuação das Instituições Especializadas}

Como já foi observado, no Brasil as instituições especializadas foram marcos históricos na oferta dos serviços de Educação Especial. Em Manaus não ocorreu de forma diferente. As críticas aos serviços de Educação Especial ofertados pelas instituições dizem respeito à pouca ênfase na questão pedagógica do ensino:

As instituições especializadas ofereciam serviços de atendimento com base num conjunto de terapias individuais (Fisioterapia, Fonoaudiologia, Psicologia, Psicopedagogia etc) e pouca ênfase era dada à atividade acadêmica, que não ocupava mais do que uma pequena fração do horário dos alunos com deficiência (MARQUES, 2010, p.41).

No atual cenário, pode-se verificar que o Estado do Amazonas possui várias organizações não governamentais: (a) Associação de Pais e Amigos dos Excepcionais APAE; (b) Associação de Amigos do Autista no Amazonas - AMA/AM; (c) Associação Amazonense de Integração de Pais de Deficientes Mentais - ADEME; (d) Associação Pestalozzi do Amazonas; (e) Associação dos Deficientes Físicos do Amazonas - ADEFA entre outras (ONGS BRASIL, 2017; VINENTE, 2017).

As instituições especializadas contribuíram, de certo modo, para a ampliação do atendimento aos estudantes público-alvo da Educação Especial. Com a implantação de novas classes especiais no fim da década de 1980 foram firmados convênios com instituições não governamentais, como APAE, Pestalozzi e diversas associações constituídas por familiares de estudantes com deficiência.

Considerando o recorte que faremos na apresentação dos dados optamos por apresentar apenas as instituições mais antigas do município.

\subsection{O Instituto Montessoriano Álvaro Maia (1943)}

Em Manaus, o início do atendimento às pessoas com deficiência ocorreu por meio da iniciativa privada, com a implantação do Instituto Montessoriano Álvaro Maia em 1943. Localizava-se em um sítio na Rua Paraíba, atual Avenida Jornalista Humberto Calderaro Filho, atendendo crianças com as mais diferentes deficiências (NASCIMENTO; OLIVEIRA; MARINHO, 2007; BATISTA, 2015). Em relato feito por Costa (2010) podemos observar um pouco a descrição do Instituto Montessoriano Álvaro Maia:

mandou construir no jardim que havia em seu entorno, um relevo terrestre com lagos, montanha, rios etc., para o ensino de geografia. Com o auxílio do Governo do Estado, que pagava professores e lhes propiciava cursos de especialização em educação de surdos-mudos, fora do Estado. Suas filhas, Rita Araújo (esposa de Umberto Calderaro Filho) especializou-se em trabalho com surdos-mudos e fez estágio com padre redentorista Eugênio, um dos maiores especialistas no assunto, e Tereza Araújo, que especializou-se em método braile e as duas deram aulas no Instituto (s.p.).

As ações pioneiras de Educação Especial desenvolvidas em Manaus com início na década de 1940 eram filantrópicas. O Estado contribuía com a formação de professores e a Igreja Católica ofertava cursos voltados para aperfeiçoamento das pessoas que atuavam na 
área da surdez. O fragmento a seguir, apresenta traços da filantropia, marca dos serviços de Educação Especial ofertados inicialmente na cidade de Manaus:

Todo o trabalho do Instituto era mantido com a contribuição mens al através de um carnet de comerciantes como J. G. Araújo, J. Rufino, J. S. Amorim, a ajuda de comerciantes do Mercado Municipal Adolfo Lisboa, que lhes davam alimentos e outros gêneros alimentícios, membros ilustres da sociedade e com a ajuda do Governo do Estado (COSTA, 2010, s.p.).

Mesmo que André Vidal de Araújo fosse vinculado ao Poder Judiciário pode-se observar ao longo dos relatos a dificuldade na manutenção do Instituto Montessoriano. Dessa forma, o trabalho realizado era financiado por doações provenientes, principalmente de comerciantes do Mercado Municipal Adolfo Lisboa, localizado no Centro Histórico de Manaus.

Além das doações recebidas em alimentos, o Instituto também contava com a contribuição de pessoas ligadas ao Poder Executivo. Os relatos mostram que os surdos também se engajavam para manter o Instituto em funcionamento. Um dos exemplos refere-se ao cenário em que André Vidal de Araújo era "[...] ajudado pelo surdo mudo Moacir, usando uma carroça puxada por um só cavalo, [...] recolhendo doações de alimentos. Não há notícias de que um só comerciante tenha se recusado à contribuição" (COSTA, 2010, s.p.).

Considerando o exposto, o Instituto Montessoriano encerrou suas atividades em 1974 (BATISTA, 2015). Até o momento não tivemos acesso à fontes históricas que nos permitam analisar os motivos que levaram ao fechamento da instituição. $O$ que os dados nos possibilitaram aferir até o momento foi a incorporação do espaço à Secretaria Municipal de Educação, tendo em vista que o endereço é o mesmo do prédio que sediou posteriormente o Núcleo de Educação Especial.

No entanto acreditamos que estudos de outros pesquisadores, principalmente utilizando-se de jornais impressos da época, poderão potencializar dados relevantes para a reconstituição do histórico desses serviços, bem como o quantitativo de alunos atendidos na instituição e aspectos da qualificação dos profissionais que atuavam no local.

\subsection{A Associação de Pais e Amigos dos Excepcionais (Apae-Manaus) 1973}

Reconstituir o histórico das instituições especializadas que ofertaram os serviços de Educação Especial nos séculos XIX e XX tem se apresentado como um desafio para os pesquisadores da área. Ao discutirem sobre a história da Apae em Manaus, Fidelis e Miki (2017) abordaram sobre a dificuldade de se encontrar fontes de pesquisas organizadas que subsidiem a pesquisa histórica sobre as instituições educacionais para as pessoas com deficiência.

Em Manaus, a APAE foi fundada em 4 de maio de 1973, autorizada como Associação Filiada pela APAE Nacional a utilizar a marca sob o registro $n^{\circ} 192$. No âmbito educacional, as atividades começaram a ser realizadas após publicação da autorização do Conselho Estadual de Educação do Amazonas, por meio da Resolução nº 102/1994. A equipe da instituição era constituída por um pequeno grupo de professores, voluntários e outros profissionais qualificados para trabalhar com esse público (FIDELIS; MIKI, 2017; FENAPAES, 2018).

Hoje, a APAE funciona em sede própria à Avenida Perimetral S/N, Parque 10, na zona centro-sul de Manaus. De acordo com seu Regimento, apresenta um caráter cultural, assistencial e educacional sem fins lucrativos, tendo como finalidade a promoção de medidas de âmbito municipal que visem não só o desenvolvimento das potencialidades das pessoas com necessidades especiais, mas também a inclusão destes na sociedade amazonense. 
A APAE mantém a Escola Ilza Garcia, ofertando serviços especializados desde 1976, cuja especificidade só foi reconhecida no ano 2000. Nesta escola funcionam 18 salas de aula de Educação Infantil, Oficinas Pedagógicas, Oficinas Profissionalizantes e diversos atendimentos (FIDELIS; MIKI, 2017; FENAPAES, 2018).

A equipe multidisciplinar atual é composta por professores, psicólogos, fonoaudiólogos, assistentes sociais, fisioterapeutas, terapeutas ocupacionais, médicos e dentistas. A instituição também mantém parcerias e convênios com vários segmentos da sociedade ofertando diversos serviços. Ao considerarmos o pioneirismo da APAE na oferta dos serviços especializados pode-se observar a atuação dessa instituição como referência no âmbito da capital amazonense.

\subsection{A Associação Pestalozzi (1979)}

O Instituto Pestalozzi, em nível nacional, teve sua fundação no ano de 1926 (MAZZOTTA, 2005; JANNUZZI; CAIADO, 2013). No estado do Amazonas, o Governo do Estado, por meio da Secretaria de Estado das Pessoas com Deficiência desenvolveu convênios com a Pestalozzi nos municípios de Boa Vista dos Ramos, Coari, Manaquiri, Maués, Manicoré, Manaus, Nova Olinda do Norte, Parintins e Tonantins (SEPED, 2015).

$\mathrm{Na}$ capital amazonense, a instituição atende principalmente pessoas com deficiência intelectual. Trata-se de uma entidade filantrópica, que operaciona suas ações mediante convênios com órgãos públicos, doações de amigos, voluntários e funcionários. Foi criada no ano de 1979, desenvolvendo ações educativas por meio do Centro de Ensino Especial Helena Antipoff.

$\mathrm{O}$ ingresso de estudantes na instituição se dá por uma avaliação multidisciplinar, realizada por uma equipe constituída de assistente social, fisioterapeuta, médico e outros profissionais. Oferta atividades físicas, oficinas de artesanato, cursos laborais e oficinas pedagógicas. Os professores são especializados em Educação Especial e atendem aproximadamente 150 estudantes em um espaço localizado no Pólo Industrial de Manaus.

\subsection{A Associação dos Deficientes Físicos do Amazonas - ADEFA (1980)}

De acordo com informações disponibilizadas em seu blog, a $A D E F A$, Associação dos deficientes Físicos do Amazonas, foi criada em 29 de julho de 1980. Trata-se de uma entidade filantrópica sem fins lucrativos, que "[...] vem oferecendo às pessoas com deficiência, atendimento global, no intuito de melhorar a qualidade de vida e sua inclusão na vida produtiva e social do nosso estado" (ADEFA, 2018). Atualmente, a Associação conta com 9.750 sócios, dos quais, segundo informações da instituição, 95\% estão abaixo da linha da pobreza.

A Lei $n^{\circ} 1.162$ de 31 de outubro de 2007 considerou de utilidade pública a ADEFA, aplicando no âmbito da Prefeitura de Manaus, as providências necessárias (MANAUS, 2007). A instituição também participou das ações do Plano Nacional de Qualificação das Pessoas com Deficiência, da Secretaria de Direitos Humanos da Presidência da República (SDH/PR). Tal ação buscou garantir o acesso aos cursos oferecidos nos Institutos Federais, no Senai (Serviço Nacional de Aprendizagem Industrial), no Sesi (Serviço Social da Indústria) e Sest Senat (Serviço Social do Transporte e Serviço Nacional da Aprendizagem do Transporte).

Sobre a atuação da ADEFA em âmbito educacional, até o momento, no contexto PPGE/UFAM, não identificamos nenhuma pesquisa voltada para análise do papel dessa e de outras instituições na oferta dos serviços de Educação Especial no município de Manaus.

No próximo item serão abordadas algumas ações governamentais desenvolvidas no município de Manaus. 


\section{As ações governamentais}

No Amazonas, os registros de atendimento especializado no ensino regular são de 1982. Esse atendimento foi ofertado aos primeiros estudantes "deficientes mentais e auditivos", na Unidade Educacional Euclides da Cunha (BATISTA, 2015; JANNUZZI, 2004). Na literatura não há indícios de serviços de Educação Especial ofertados pelo Poder Público na região aos estudantes com deficiência após essa época. Dessa forma, observamos uma lacuna na cronologia até meados de 1970.

A década de 1970 marcou no Brasil o início da institucionalização da Educação Especial, principalmente no que diz respeito à centralização e ao planejamento, por meio dos planos setoriais de Educação. No âmbito da rede pública municipal de ensino, a Semed foi constituída por intermédio da Lei Municipal no 1.094/1970, tendo como o primeiro secretário, Aldimar Marinho Sampaio (MANAUS, 2017; VINENTE, 2017).

No âmbito da rede pública estadual de ensino, os primeiros professores foram especializados no Rio de Janeiro, em convênio realizado entre a SEDUC e o MEC. Em 1972, organizou-se no contexto da SEMED o atendimento educacional aos alunos com deficiência visual, auditiva e mental nas classes especiais implantadas nas escolas regulares (NASCIMENTO; OLIVEIRA; MARINHO, 2007; MARQUES, 2010).

Em 1973, com a criação do Centro Nacional de Educação Especial (CENESP) no âmbito do Ministério da Educação (MEC) pode-se dizer que houve a implantação dos subsistemas de Educação Especial nos Estados e a expansão da área junto ao ensino regular (FERREIRA, 1992).

Com a estruturação da SEMED e o grande número de professores que atuavam sem formação mínima houve a necessidade de capacitação dos profissionais da educação e atualização dos que já eram professores da rede. Ainda na década de 1970, a Secretaria já possuía 128 escolas que atendiam ao $1^{\circ}$ Grau (SEMED, 2017). É importante frisar que nesse contexto histórico a Educação Básica ainda não era obrigatória e gratuita em sua totalidade.

Em 1975, a SEDUC implantou a Coordenação de Programa de Assistência ao Educando Especial, constituída por uma equipe multiprofissional. Essa ação foi estendida aos municípios do interior do Amazonas (NASCIMENTO; OLIVEIRA; MARINHO, 2007; MATOS; VINENTE, 2013; BATISTA, 2015).

Durante o período de democratização do Estado brasileiro, mais especificamente entre os anos de 1989 e 1992, a SEMED passou a atender aos estudantes nas diferentes modalidades e níveis de ensino (VINENTE, 2017). No ano de 1989, essa Secretaria realizou um levantamento para identificar o quantitativo de crianças que necessitavam de atendimento educacional especializado. Durante esse período, com base nos dados de Santos (1998) foram identificadas 72 crianças.

$\mathrm{O}$ auge da implantação dos serviços de Educação Especial no município se deu especificamente no ano de 1991, com a institucionalização dessa modalidade por meio da publicação da Lei $n^{\circ}$ 050/1991. De acordo com essa lei, a Educação Especial era "[...] voltada para atender as pessoas portadoras de deficiência visual, auditiva, mental, as infra-dotadas ${ }^{2}$ e as superdotadas" (MANAUS, 1991). Foi somente a partir de 1991 que as matrículas referentes à Educação Especial passaram a compor as estatísticas da SEMED. Fato esse que se deu um ano após a realização da Conferência Mundial sobre Educação para Todos na Tailândia (VINENTE, 2017).

A instituição dos Conselhos Escolares a partir da publicação da Lei de Diretrizes e Bases da Educação (BRASIL, 1996) e a criação dos Conselhos Estaduais e Municipais de Educação consolidou amplo espaço para discussão da política educacional. No âmbito da SEMED, somente a partir da publicação da Lei no 377/1996 é que houve a criação do Conselho Municipal de Educação (CME).

\footnotetext{
${ }^{2}$ Estudante com baixa linha de raciocínio, com pensamento limitado ou lento.
} 
Nesse sentido, visando resgatar algumas ações governamentais executadas nesse período, serão apresentados: o Centro de Triagem e Avaliação Diagnóstica - CETRIDE; o Núcleo de Educação Especial; o Serviço de Avaliação Diagnóstica da Educação Especial (SADEM) e; o Complexo Municipal de Educação Especial André Vidal de Araújo.

\subsection{Centro de Triagem e Avaliação Diagnóstica}

Em 1976 houve a criação do Centro de Triagem e Avaliação Diagnóstica - CETRIDE (MATOS, 2008; MARQUES, 2010), um dos primeiros centros constituídos por equipe técnica multiprofissional do Amazonas. O CETRIDE era constituído por médicos, psicólogos, pedagogos e professores. Eram realizadas avaliações clínico-educacionais dos estudantes com deficiência matriculados na rede estadual de ensino, os quais posteriormente eram encaminhados às escolas ou classes especiais.

Eram realizadas atividades de orientação aos pais e de formação dos professores. Foram realizados inúmeros cursos para professores e pedagogos da rede estadual de ensino, nos quais eram trabalhados conteúdos relacionados às especificidades da deficiência auditiva, visual e mental. O encerramento das atividades do CETRIDE se deu, provavelmente, no ano de 2002 (MARQUES, 2010).

\subsection{Núcleo de Educação Especial}

No ano de 1991, ao serem implementados os serviços de Educação Especial na Semed (SANTOS, 1998; MATOS, 2008), também foi criado o Núcleo de Educação Especial (VINENTE, 2017). O objetivo do Núcleo era coordenar, acompanhar e avaliar os Programas de Educação Especial da rede municipal de ensino, como sinalizado por Santos (1998), Matos (2008) e Vinente (2017).

Segundo Santos (1998), a criação do Núcleo de Educação Especial amparou-se no inciso III, do artigo 208 da Constituição Federal e no artigo 347, inciso II, da Lei Orgânica do Município de Manaus, o que culminou posteriormente com a publicação da Lei 050/1991.

Ao longo da literatura e dos documentos analisados não visualizamos mais os termos Núcleo de Educação Especial, apenas menção à Seção de Educação Especial. O Manual de Educação Especial da Semed apresenta como se dava o trabalho dos profissionais vinculados a essa Seção:

A equipe que compõe a seção de Educação Especial realiza acompanhamento técnico-pedagógico de forma sistemática aos professores e técnicos que atuam na área, tendo dentre as suas prioridades a busca constante do conhecimento através da participação em seminários, cursos, palestras etc., objetivando aprimorar mais o atendimento aos portadores de necessidades educativas especiais (MANAUS, s.d.).

Na perspectiva de propor assessoramento aos professores e demais profissionais que atuavam no ensino regular observa-se no detalhamento do documento a priorização dos cursos de formação por meio de cursos, seminários e palestras. Anteriormente à criação do Serviço de Avaliação Diagnóstica da Educação Especial do Município (Sadem), o Manual da Educação Especial da Semed (MANAUS, s.d.) reforçava que pelo fato da Secretaria não possuir um Centro de Triagem, os estudantes da rede pública municipal de ensino eram encaminhados ao CETRIDE.

Essa triagem era desenvolvida mediante um convênio entre a Prefeitura de Manaus e o Governo do Estado do Amazonas. Os estudantes que estavam nas classes especiais ou que 
precisavam de um atendimento educacional, mas não possuíssem uma súmula pedagógica, eram encaminhadas ao CETRIDE pela equipe da Seção de Educação Especial. No próximo item, descreveremos o processo em torno do Serviço de Avaliação Diagnóstica da Educação Especial que foi implementado no município, marcando assim o término do convênio com o Governo do Estado e a independência na proposição de serviços de atendimento especializado aos estudantes da rede.

\subsection{Serviço de Avaliação Diagnóstica da Educação Especial (SADEM)}

A seção responsável pela Educação Especial na Semed (Núcleo) passou em 1997 por uma reestruturação, incorporando seis profissionais que realizavam assessoria pedagógica aos professores da Educação Especial (SANTOS, 1998). No mesmo ano, de acordo com Matos (2008), houve a criação do Serviço de Avaliação Diagnóstica da Educação Especial do Município (SADEM). Esse setor era constituído por oito profissionais das áreas de saúde e educação, os quais realizavam a avaliação diagnóstica dos estudantes encaminhados.

Para Santos (1998), o objetivo do Sadem era avaliar e diagnosticar os estudantes para o atendimento nos serviços de Educação Especial e Ensino Fundamental da rede municipal de ensino. De acordo com a autora, antes disso, a avaliação e o diagnóstico eram realizados por meio de um convênio com a Secretaria de Educação do Estado (SEDUC). O Sadem, durante a gestão do prefeito Alfredo Nascimento, vinculava-se ao Departamento de Ensino da SEMED e localizava-se na Rua Paraíba ${ }^{3}, n^{\circ} 230$, bairro São Francisco (MANAUS, 1997).

A equipe do SADEM era constituída por um assistente social, um pedagogo, um psicopedagogo, dois psicólogos, dois fonoaudiólogos e dois professores (SANTOS, 1998). Ao recuperar esses aspectos históricos encontramos na literatura uma discordância sobre a composição da equipe do Sadem por oito (MATOS, 2008) ou nove profissionais (SANTOS, 1998).

Em Cartilha de Orientação entregue às escolas (MANAUS, 1997), eram explicitados os procedimentos para acesso aos serviços do Sadem. Informava-se que, se o aluno apresentasse indícios de dificuldades de aprendizagem, o professor, técnico ou diretor deveriam buscar apoio da Seção de Educação Especial. Assim sendo, um técnico do SADEM realizaria uma visita para checar a situação do aluno. Detectado então problema durante a visita seria preenchido um formulário de encaminhamento ao SADEM, que deveria ser entregue à Seção de Educação Especial.

Após a chegada da ficha de encaminhamento do estudante ao SADEM era agendada uma triagem, na qual o estudante era submetido a uma avaliação diagnóstica. Na época, essa avaliação era realizada por meio de testes psicopedagógicos e anamnese social, que envolviam a família e o estudante (MANAUS, 1997). Ainda sobre o diagnóstico dos estudantes, tivemos acesso às seguintes informações:

O diagnóstico é um processo contínuo, que inicia com a identificação do aluno, passando pelo encaminhamento, atendimento $\mathrm{e}$ acompanhamento. A finalidade deste procedimento é fornecer informações reais e objetivas, para que sejam adequadas ao indivíduo portador de necessidades educativas especiais (MANAUS, 1997, s.p.).

Em 1997, os estudantes atendidos pelo SADEM eram encaminhados da pré-escola e da $1^{a}$ à $4^{a}$ series, que atualmente correspondem à parte da Educação Infantil e anos iniciais do Ensino Fundamental, até a faixa etária dos 15 (quinze) anos (MANAUS, 1997; SANTOS, 1998). Posteriormente, segundo observado no estudo de Matos (2008), o

\footnotetext{
${ }^{3}$ As fontes documentais apresentavam que este era o mesmo endereço do Instituto Montessoriano Álvaro Maia. Funcionava de segunda à quinta, das $8 \mathrm{~h}$ às $18 \mathrm{~h}$, e nas sextas ocorriam os estudos de caso.
} 
SADEM seria transformando no Centro Municipal de Educação Especial (CMEE), mas antes disso, como pode ser visualizado nos registros, o SADEM dá lugar à Escola Municipal José Salomão Schwartzman, funcionando inclusive no mesmo lugar, como disposto no anexo da Lei ${ }^{\circ} 452 / 1998$.

\subsection{Complexo Municipal de Educação Especial}

Em 2003, a Resolução $n^{\circ}$ 005/CME assegurava no parágrafo único do artigo $3^{\circ}$ que o sistema de ensino municipal, entendido aqui como SEMED, deveria "[...] constituir e fazer funcionar um centro responsável pela Educação Especial, dotado de recursos humanos, materiais e financeiros [...]" que viabilizassem e dessem sustentação ao processo de "construção da educação inclusiva" (MANAUS, 2003, art. 3º. Por conta disso, até 2007, após desativação da escola José Salomão Schwartzman, o Complexo de Educação Especial funcionou sob a denominação de Centro de Educação Especial.

A Lei $\mathrm{n}^{\circ}$ 1.102, de 09 de março de 2007, ao criar o Complexo Municipal de Educação Especial André Vidal de Araújo, atribuiu à SEMED a fiscalização e o cumprimento da lei. O Complexo foi visualizado na região como um centro de referência para atendimento aos estudantes público-alvo da Educação Especial (PAEE), por dispor de uma equipe multidisciplinar. Notam-se poucas alterações em relação aos profissionais que atuavam no Núcleo de Educação Especial, no início da década de 1990.

Os professores e demais profissionais que atuam no Complexo são assessores nas DDZs e acompanham o trabalho desenvolvido durante o Atendimento Educacional Especializado (AEE) das escolas municipais vinculadas à Secretaria. De acordo com a Resolução no 010/CME/2011 a equipe é composta por pedagogos, psicopedagogos, fonoaudiólogos, psicólogos, assistentes sociais, terapeutas ocupacionais, fisioterapeutas e odontólogos (MANAUS, 2011).

Cabe salientar que, principalmente para as crianças oriundas de famílias de baixa renda, a avaliação multiprofissional é um dos maiores serviços ofertados pela rede municipal de ensino. Convém destacar que, por exemplo, no Sistema Único de Saúde (SUS) a marcação de uma consulta com especialistas é demorada e inviabiliza a avaliação dos estudantes PAEE, principalmente para a emissão de laudo médico. No caso do CMEE, a avaliação desses estudantes ocorre de modo mais rápido, possibilitando que estudantes em vulnerabilidade econômica tenham acesso a uma avaliação multiprofissional gratuita (VINENTE, 2017).

Em 2015, a Resolução n ${ }^{\circ}$ 038/CME trouxe uma nova configuração para a manutenção do Complexo Municipal de Educação André Vidal de Araújo, atribuindo no artigo 54 que o Complexo "[...] como estabelecimento inclusivo, baseado na reconstrução e reconhecimento das diferenças e práticas pedagógicas pautadas em novas estratégias educacionais, oferecerá as oficinas pedagógicas" (MANAUS, 2015, art. 54).

\section{Os tipos de serviços ofertados}

Nesse item apresentaremos aspectos relacionados aos serviços de Educação Especial ofertados em Manaus. Tais serviços estão previstos no parágrafo $1^{\circ}$, do artigo 58 da Lei de Diretrizes e Bases da Educação (BRASIL, 1996), podendo ser realizado em classes, escolas ou serviços especializados. Dessa forma, apresentaremos esses serviços estruturados nos tópicos: (1) Escolas de Educação Especial; (2) Classes Especiais; (3) Salas de Recursos; e, (4) Salas de Recursos Multifuncionais. 


\subsection{As escolas de Educação Especial}

O Decreto n 87.062/1982 ao dispor sobre a organização administrativa do MEC, definiu o Centro Nacional de Educação Especial (CENESP) como autônomo. O artigo 29 do Decreto apresentou a finalidade do CENESP, que se baseava em:

subsidiar a formulação da Política Nacional relativa à educação de excepcionais; planejar, coordenar e promover o desenvolvimento da educação especial no período pré-escolar, nos ensinos de $1^{\circ}$ e $2^{\circ}$ graus, supletivo e superior, para os deficientes e os superdotados (BRASIL, 1982, s.p.).

Ainda em 1982 foram criadas em Manaus as seguintes escolas especiais: (1) Escola Estadual Augusto Carneiro dos Santos - para estudantes com deficiência auditiva; (2) Escola Estadual Joana Rodrigues Viana - para estudantes com deficiência visual; (3) Escola Estadual Diofanto Monteiro - para estudantes com deficiência mental (OLIVEIRA, 2007; MARQUES, 2010; CORDEIRO, 2016).

Em 1995, por meio do Decreto ${ }^{\circ} 16.593$, foi criada a Escola Estadual Manuel Maçal de Araújo, destinada ao atendimento de estudantes com deficiência mental menores de 14 anos (MARQUES, 2010; CORDEIRO, 2016). Atualmente, a escola possui estudantes com deficiências múltiplas, autismo, síndrome de Down e Paralisia Cerebral.

Manoel Marçal de Araújo foi patrono da escola e também o fundador da Associação dos Deficientes Físicos do Amazonas (ADEFA). Após sofrer um grave acidente, aos 28 anos, ficou tetraplégico. Em 1989, elegeu-se vereador, cargo que exerceu até o ano de 1992. Faleceu no ano seguinte, aos 56 anos, deixando um legado de luta à causa das pessoas com deficiência física (CORREIO DA AMAZÔNIA, 2015).

Em 1998, a Lei $n^{\circ}$ 452/1998, criou na estrutura administrativa da SEMED, a Escola Municipal José Salomão Schartzman (MANAUS, 1998). Além dessa, a Escola Emerson F. Prestes também atendia estudantes da Educação Especial (VINENTE, 2017).

Com a transformação do SADEM no Centro Municipal de Educação Especial André Vidal de Araújo (CMEE) essas escolas foram extintas. Sendo assim, o Centro passou a congregar os profissionais oriundos delas, passando a ser o único local a ofertar os serviços de Educação Especial em âmbito municipal. Posteriormente, o Centro deixa de ser uma escola especial e passa a dar suporte aos estudantes da rede municipal de ensino, mantendo as oficinas pedagógicas.

\subsection{As classes especiais}

Na década de 1970 foi implantada a primeira classe especial para estudantes com deficiência auditiva no âmbito da SEDUC (LIMA, 1992; JORNAL DA CFFa, 2008). A fonoaudióloga Dulcinéia Lima foi uma das fundadoras dos serviços de Educação Especial na cidade de Manaus, tendo estudado no Centro de Pesquisa em Terapia da Palavra (hoje Universidade Estácio de Sá) (JORNAL da CFFa, 2008).

Segundo relatos de Dulcinéia Lima era comum que muitos profissionais viessem de fora e partissem. Ao atuar na Fundação Pestalozzi e na APAE, a fonoaudióloga relatou juntamente com outros profissionais que estruturou o Centro de Triagem e Avaliação Diagnóstica, realizando a avaliação das crianças e orientando aos pais (JORNAL DA CFFa, 2008).

Ferreira (1992) problematizava a questão da oferta dos serviços de Educação Especial por meio das classes especiais. Segundo ele: 
É bastante provável que exista entre os educadores especiais uma visão quase consensual sobre a inadequação dessas classes especiais como um serviço que esteja traduzindo o direito à educação dos portadores de necessidades educacionais especiais. Pensamos ser oportuno debater a natureza desse consenso e discutir formas alternativas ou complementares de atuação: queremos fechar as classes especiais ou trocar sua população, seu currículo, seu corpo docente, ou queremos uma população diferente em outro tipo de arranjo educacional (FERREIRA, 1992, p. 105)

Tal problematização muito tem a ver com o estudo de Santos (1998), realizado na década de 1990, o qual verificou que os alunos encaminhados às classes especiais em Manaus possuíam histórico de fracasso escolar e apresentavam dificuldades de aprendizagem. Assim sendo, "quase todos/as sabiam ler e escrever, ainda que, minimamente" (p. 43).

Em uma época em que o debate sobre a exclusão das classes especiais intensificou-se no Brasil, na cidade de Manaus, durante o ano de 1997 havia apenas sete (7) classes especiais na rede pública municipal de ensino. No âmbito da SEMED, as classes atendiam também estudantes com "deficiência mental educável", deficiência auditiva e deficiência visual (SANTOS, 1998).

Considerando as transformações ocorridas no espaço urbano da cidade de Manaus observamos a incidência de poucas classes especiais na zona norte. Atualmente, essa zona é uma das maiores da cidade. Averiguamos também elevado número de classes especiais na zona leste, por ser esta zona na década de 1990 a que mais crescia em âmbito populacional e geográfico.

As classes especiais foram definidas na legislação municipal como modalidade de atendimento. De acordo com o documento, a classe especial funcionava em escolas do ensino regular, "[...] organizadas de modo adequado ao processo de ensino aprendizagem, disponibilizando métodos, técnicas, recursos humanos, capacitados, reconhecendo-se e valorizando-se as singularidades, diferenças e potencialidades dos educandos" (MANAUS, 2003).

Atualmente, a maioria das classes especiais que atendem aos estudantes PAEE em Manaus encontram-se distribuídas nas DDZs V e VI, ou seja, em uma das zonas mais populosas da cidade. De acordo com a representante da Gerência de Educação Especial (GEE), a legislação educacional ainda garante a existência das classes especiais, por isso as mesmas encontram-se em funcionamento na SEMED. Mesmo que os serviços das classes especiais ainda sejam ofertados, a Resolução $n^{\circ}$ 011/CME/2016 não menciona nenhum aspecto desse tipo de atendimento (MANAUS, 2016).

\subsection{Salas de Recursos}

Em 1997, a sala de recursos era considerada pela legislação do município como um "espaço adequado para o atendimento de alunos que apresentavam dificuldades no ato de aprender através de material didático, com blocos lógicos, jogos de atenção, memorização etc" (MANAUS, 1997, s.p.). Ao observarmos a definição da sala, visualizamos mais aspectos de sua organização do que elementos para identificação do público-alvo atendido nela.

As salas de recursos, que ao longo de muitos anos ofertou o AEE aos estudantes com deficiência da rede municipal de ensino, basearam-se em espaços de atendimento aos estudantes surdos e cegos matriculados ${ }^{4}$ entre o $6^{\circ}$ e o $9^{\circ}$ ano do Ensino Fundamental (MANAUS, 2003). Mais tarde, a Resolução $\mathrm{n}^{\circ}$ 10/CME/2011 insere as salas de recursos e as salas de recursos multifuncionais como parte dos serviços de AEE, devendo ser ofertados de forma individual ou em pequenos grupos, durante o contraturno (MANAUS, 2011).

\footnotetext{
${ }^{4} \mathrm{O}$ texto original da resolução mantém a terminologia "integrados", optamos por inserir aqui "matriculados".
} 
O Plano Nacional de Educação (PNE) vigente (BRASIL, 2014) estabeleceu como meta para a Educação Especial a universalização para estudantes PAEE dos quatro aos dezessete anos, o acesso à Educação Básica e ao AEE, preferencialmente na rede regular de ensino, com a garantia de sistema educacional inclusivo, por meio de "[...] salas de recursos multifuncionais, classes, escolas ou serviços especializados, públicos ou conveniados" (BRASIL, 2014, n.p). O texto do atual Plano Municipal de Educação - PME (MANAUS, 2015) também mantém os mesmos locais para a oferta desses serviços.

Atualmente, as salas de recursos são espaços criados pela SEMED, diferentemente das salas de recursos multifuncionais, que são implantadas a partir de recursos do Governo Federal. Na rede pública municipal de ensino, o quantitativo atual é de 29 salas. Essas se encontram distribuídas da seguinte forma: (a) 6 na zona sul; (b) 6 na zona oeste; (c) 9 na zona norte; (d) e 8 na zona leste (SEMED, 2017; VINENTE, 2017).

\subsection{Salas de Recursos Multifuncionais}

As salas de recursos multifuncionais (SRM), de acordo com o Decreto $n^{\circ} 7.611 / 2011$, são "[...] ambientes dotados de equipamentos, mobiliários e materiais didáticos e pedagógicos para a oferta do atendimento educacional especializado" (BRASIL, 2011, art. $5^{\circ}, \S 3^{\circ}$ ). Dados do MEC apontaram que até o ano de 2011 foram implantadas no Amazonas aproximadamente 472 SRM (sendo 444 do tipo I e 28 do tipo II). Em Manaus, os mesmos dados apontam a implantação de 76 SRM (sendo 65 do tipo I e 11 do tipo II). Destas salas, 47 são vinculadas a rede municipal de ensino da cidade de Manaus e 29 a rede estadual de ensino (VINENTE, 2017).

De acordo com Santos e colaboradores (2017), o número de salas de recursos multifuncionais implantadas em Manaus não acompanhou o quantitativo de matrículas dos estudantes da Educação Especial no sistema regular de ensino, representando um déficit de $40 \%$ para o atendimento a esse alunado. Vinente e Oliveira (2017) também concordam que ao se levar em consideração o quantitativo de estudantes PAEE matriculados na rede de ensino, o número de salas ainda é insuficiente para a oferta efetiva do AEE.

\section{Considerações Finais}

Ao considerarmos os dados apresentados e discutidos no texto, o trabalho propôs-se descrever e analisar o histórico da oferta dos serviços de Educação Especial em Manaus entre 1982 e 2016. Ao percorrermos a história da Educação Especial brasileira encontramos semelhanças relacionadas às formas de organização do trabalho pedagógico para 0 atendimento às necessidades dos estudantes público-alvo em Manaus.

Ao mesmo tempo em que se fortalece no Brasil, principalmente nas décadas de 1970 e 1980 a proliferação de organizações não governamentais que buscavam subvenções do Poder Público para sua manutenção, isso também ocorre em Manaus do mesmo modo. É claro que no tocante à formação de profissionais principalmente para atuação junto a esses estudantes pouco houve de avanço.

Se na década de 1970 os professores deslocavam-se para os estados do sudeste para cursar ações de capacitações no Instituto Nacional de Educação para Surdos (INES) e no Instituto Benjamin Constant (IBC), ainda hoje a região carece de cursos de graduação ou pós-graduação stricto sensu em Educação Especial. A criação de uma linha de pesquisa em Educação Especial ocorreu na UFAM apenas no ano de 2013, sendo necessário anteriormente que pesquisadores interessados na temática adequassem seus projetos a outras linhas de pesquisa.

Além da atuação das instituições especializadas na oferta dos serviços observamos iniciativas do Poder Público tais como: (a) criação do CETRIDE em 1976; (b) criação do 
Núcleo de Educação Especial após um longo tempo sem políticas públicas implementadas no município para essa população; (c) a institucionalização da Educação Especial no município por meio da Lei ${ }^{\circ}$ 050/1991; (d) funcionamento do SADEM desde 1997 enquanto serviço essencial para identificação do alunado da Educação Especial e encaminhamento destes ao ensino regular e; (e) criação do Complexo Municipal de Educação Especial em 2007.

Em relação aos serviços executados no âmbito da Educação Especial verificamos pouca variedade, identificando prioritariamente o atendimento em classes e escolas especializadas, bem como em salas de recursos e salas de recursos multifuncionais. Não foi possível identificar nesse estudo aspectos mais pontuais sobre as oficinas pedagógicas, estimulação precoce/essencial, ensino com professor itinerante e ensino domiciliar/hospitalar.

Com as alterações na legislação educacional e as diretrizes que versam sobre a Política Nacional de Educação Especial na Perspectiva da Educação Inclusiva observou-se em Manaus novas configurações dos serviços especializados, porém em moldes antigos. Visualiza-se ainda a avaliação multidisciplinar inicial para identificação dos estudantes público-alvo da Educação Especial, avaliação essa que focaliza os aspectos clínicos aos pedagógicos.

A implantação das salas de recursos multifuncionais estagnou, e a cada ano cresce o quantitativo de estudantes público-alvo matriculados nos sistemas públicos estadual e municipal de ensino. As classes especiais foram mantidas nas escolas como parte dos serviços de Educação Especial, levando-se em consideração que o Decreto $n^{\circ} 7611 / 2011$ não privilegia tanto a inclusão total na rede regular de ensino, como estava posto no Decreto anterior.

Nesse cenário, considerando a ausência de estudos sobre os aspectos históricos desses serviços, o trabalho apontou lacunas que podem ser preenchidas por outras pesquisas, de forma a constituir principalmente um conhecimento científico sobre as políticas públicas implementadas e práticas pedagógicas desenvolvidas. Precisamos, ao analisar instituições ou mesmo políticas públicas, contextualizar a presença da pessoa com deficiência em diferentes espaços.

Dessa forma, vários questionamentos podem ser realizados: (a) como evoluiu o conceito de educação especial/inclusiva na legislação educacional estadual e municipal? (b) que ações governamentais foram desenvolvidas ao longo da história para a empregabilidade dos estudantes que compõem o público-alvo da Educação Especial? (c) como as instituições especializadas vêm desenvolvendo trabalhos que visem o pleno desenvolvimento desses estudantes? quais registros históricos temos sobre as instituições especializadas em jornais impressos ao longo do tempo?

Não pretendemos aqui esgotar em um único texto aspectos históricos de serviços desenvolvidos em uma região complexa como a capital amazonense, que guarda especificidades e inúmeras contradições em seus contextos sociais, políticos e educacionais. No entanto, os dados vislumbrados possibilitam o desenvolvimento de outros estudos e podem contribuir para a análise de novas possibilidades de atuação junto a esse público, de modo que políticas educacionais sejam formuladas e pensadas visando garantir o direito de todos à educação.

\section{Referências}

ADEFA. Associação dos Deficientes Físicos do Amazonas. Instituição que visa inserir os Deficientes físicos em âmbito global. Disponível em: <http://adefaam.blogspot.com.br/>. Acesso em: jan. 2018

BARROS, K.F.B. Inclusão de jovens com deficiência no mercado de trabalho: avanços e desafios na cidade de Manaus - AM. 2014. 147f. Dissertação (Mestrado em Serviço Social) Instituto de Ciências Humanas e Letras, Universidade Federal do Amazonas, Manaus, 2014. 
BATISTA, C.P. Política pública de inclusão: atendimento de educandos com deficiência visual no município de Manaus/AM. 2015. 123f. Dissertação (Mestrado em Educação) Faculdade de Educação, Universidade Federal do Amazonas, Manaus, 2015.

BODGAN, R.; BIKLEN, S. Investigação qualitativa em educação. Lisboa: Porto Editora, 1994.

BRASIL. Decreto n ${ }^{\circ}$ 7.611, de 17 de novembro de 2011: dispõe sobre a educação especial, o atendimento educacional especializado e dá outras providências. Diário Oficial [da] República Federativa do Brasil, Brasília, DF, 17 nov. 2011.

BRASIL. Decreto $\mathrm{n}^{\circ}$ 87.062, de 29 de Março de 1982: Dispõe sobre a organização administrativa do Ministério da Educação e Cultura e dá outras providências. Diário Oficial [da] República Federativa do Brasil. Brasília, DF, 29 mar. 1982.

BRASIL. Lei Federal no 5.692, de 11 de agosto de 1971: fixa as Diretrizes e Bases para o ensino de $1^{\circ}$ e $2^{\circ}$ graus, e dá outras providências. Diário Oficial [da] República Federativa do Brasil, Brasília, DF, 11 ago. 1971.

BRASIL. Lei $n^{\circ}$ 4024, de 20 de dezembro de 1961: fixa as diretrizes e bases da educação nacional. Diário Oficial [da] República Federativa do Brasil, Brasília, DF, 20 dez. 1961.

BRASIL. Lei n ${ }^{\circ}$ 13.005, de 25 de abril de 2014: aprova o Plano Nacional de Educação e dá outras providências. Diário Oficial [da] República Federativa do Brasil, Brasília, DF, 13 abr. 2014.

BRASIL. Lei n 9.394, de 20 de dezembro de 1996: estabelece as diretrizes e bases da educação nacional. Diário Oficial [da] República Federativa do Brasil, Brasília, DF, 20 dez. 1996.

BRASIL. Política Nacional de Educação Especial na Perspectiva da Educação Inclusiva. Diário Oficial [da] República Federativa do Brasil, Brasília, DF, jan. 2008.

CORDEIRO, K.C.B. A inclusão de alunos com deficiência na escola estadual x na cidade Manaus-AM. 99f. Dissertação (Mestrado Profissional em Gestão e Avaliação da Educação Pública) - Faculdade de Educação, Universidade de Juiz de Fora, Juiz de Fora, MG, 2016.

CORRÊA, R.M. A formação continuada do professor para a educação de surdos na rede municipal de Manaus: repercussões na prática pedagógica. 2013. 135f. Dissertação (Mestrado em Educação) - Faculdade de Educação, Universidade Federal do Amazonas, Manaus, 2013.

CORREIO DA AMAZÔNIA. Escola Estadual de Educação Especial 'Manoel Marçal', reinaugurada em Manaus. Disponível em: <https://correiodaamazonia.com/escola-estadualde-educacao-especial-manoel-marcal-reinaugurada-em-manaus/>. Acesso em dez. 2015.

COSTA, C. André Vidal de Araújo: o homem, o humanista e o social. Manaus, 2010. Disponível em: <http://www.recantodasletras.com.br/artigos/2609897>. Acesso em: out. 2017.

FENAPAES. Apae Brasil: Federação Nacional das Apaes: nossa história. Disponível em: <http://apaebrasil.org.br/page/2>. Acesso em jan. 2018.

FERREIRA, J.R. Notas sobre a evolução dos serviços de Educação Especial no Brasil. Revista Brasileira de Educação Especial, Piracicaba, v. 1, n. 1, p. 101-106, 1992. 
FIDELIS, B.S; MIKI, P.S.R. História da Associação de Pais e Amigos dos Excepcionai em Manaus-APAE. In: ENCONTRO PARA AS POLÍTICAS PÚBLICAS PARA A PANAMAZÔNIA E CARIBE, 4., Boa Vista. Anais...Boa Vista: EDUFRR, 2017.

FIGUEIRA, E. O que é educação inclusiva. São Paulo: Brasiliense, 2011.

FONSECA, J.J.S. Metodologia da pesquisa científica. Fortaleza: UEC, 2002. Apostila

GIL, A.C. Como elaborar projetos de pesquisa. 4. ed. São Paulo: Atlas, 2008.

JANNUZZI, G.M. A educação do deficiente no Brasil: dos primórdios ao início do século XXI. Campinas: Autores Associados, 2004. https://doi.org/10.1590/S0100-15742005000100012

JANNUZZI, G.M.; CAIADO, K.R.M. Apae: 1954 a 2011: algumas reflexões. Campinas, SP: Autores Associados, 2013.

JORNAL CFFa. Conselho Federal de Fonoaudiologia. Entrevista com Dulcinéia Fonseca de Lima. 2008.

LIMA, D.F. Influência das leves alterações auditivas no processo ensino-aprendizagem. 73f. Dissertação (Mestrado em Educação) - Universidade Federal do Amazonas, Manaus, 1992.

MANAUS. Lei Municipal no 1.094, de 20 de outubro de 1970. Diário Oficial do Município de Manaus. Manaus, AM, 20 out. 1970. Disponível em: <http://www.manaus.am.gov.br/>. Acesso em jul. 2015

MANAUS. Lei Municipal no 377 de 18 de dezembro de 1996. Diário Oficial do Município de Manaus. Manaus, AM, 18 dez. 1996. Disponível em: <http://www.manaus.am.gov.br/>. Acesso em: ago. 2015.

MANAUS. Lei n 050, de 4 de janeiro de 1991: dispõe sobre a implantação da Educação Especial na Rede Municipal de Ensino. Diário Oficial do Município de Manaus. Manaus, AM, 4 jan. 1991.

MANAUS. Lei no 1.102, de 09 de março de 2007: cria o Complexo Municipal de Educação Especial André Vidal de Araújo e dá outras providências. Diário Oficial do Município de Manaus $n^{o}$ 1679. Manaus, AM, 08 mar. 2007. Disponível em: <http://www.manaus.am.gov.br/>. Acesso em: ago. 2015.

MANAUS. Lei $\mathrm{n}^{\circ}$ 452, de 26 de novembro de 1998: cria na estrutura administrativa da Secretaria Municipal de Educação, as escolas municipais que especifica e dá outras providências. Diário Oficial do Município de Manaus. Manaus, AM, 26 nov. 1998. Disponível em: <http://www.manaus.am.gov.br/>. Acesso em: ago. 2015.

MANAUS. Manual da Educação Especial da Secretaria Municipal de Educação. s.d (Apostila).

MANAUS. Resolução n ${ }^{\circ}$ 010/CME, de 28 de julho de 2011: institui os procedimentos e orientações para Educação Especial na Perspectiva da Educação Inclusiva no Sistema Municipal de Ensino de Manaus. Diário Oficial do Município de Manaus. Manaus, AM, 20 jul. 2011. 
MANAUS. Resolução no 005/CME, de 18 de dezembro de 2003: dispõe sobre procedimentos e orientações a serem observados para oferta da Educação Especial no Sistema Municipal de Ensino a partir de 2003. Diário Oficial do Município de Manaus. Manaus, AM, 18 dez. 2003.

MANAUS. Resolução $\mathrm{n}^{\circ}$ 011/CME/2016, de 02 de junho de 2016: Institui novos procedimentos e orientações para Educação Especial, na perspectiva da Educação Inclusiva, no Sistema Municipal de Ensino de Manaus. Diário Oficial do Município de Manaus. Manaus, AM, 02 jun. 2016.

MANAUS. Resolução no 038/CME, aprovada em 03 de dezembro de 2015: aprova o Regimento Geral das Unidades de Ensino da Rede Pública Municipal de Manaus, como documento que estabelece normas reguladoras de organização administrativa e pedagógica, servindo de parâmetro para a elaboração dos Regimentos Escolares das Unidades de Ensino da Semed. Diário Oficial do Município de Manaus. Ano XVII, Edição 3852. Poder Executivo - Caderno II. Manaus, AM, 18 de mar. 2016.

MANAUS. Serviço de Avaliação Diagnóstica da Educação Especial do Município - SADEM: integração: abrace essa causa. Manaus: Departamento de Ensino - Divisão de Ensino - Seção de Educação Especial, 1997 (Folder Informativo).

MARQUES, M.P.S.D. O Acesso de Pessoas com Deficiência ao Sistema Público de Ensino de Manaus na Percepção dos Professores. 2010. 149f. Tese (Doutorado em Ciências: área Psicologia) - Faculdade de Filosofia, Ciências e Letras de Ribeirão Preto, Universidade de São Paulo, Ribeirão Preto, 2010.

MATOS, M.A.S. Cidadania, diversidade e educação inclusiva: um diálogo entre a teoria e a prática na rede municipal de Manaus. 2008. 229f. Tese (Doutorado em Educação) Faculdade de Educação, Universidade Federal do Rio Grande do Sul, Porto Alegre, 2008.

MATOS, M.A.S.; VINENTE, S. A produção científica em Educação Especial no Amazonas: análise das publicações do Programa de Pós-Graduação em Educação (PPGE/UFAM) entre 1998 e 2012. In: CONGRESSO BRASILEIRO MULTIDISCIPLINAR DE EDUCAÇÃO ESPECIAL, 7., 2013. Londrina, Anais, Londrina: UEL, 2012, p. 635-645.

MAZZOTTA, M.J.S. Educação Especial no Brasil: história e políticas públicas. 5. ed. São Paulo: Cortez, 2005.

MENDES, E.G. A radicalização do debate sobre inclusão escolar no Brasil. Revista Brasileira de Educação. Rio de Janeiro, v.11, n.33, p.387-405, set./dez., 2006. https://doi.org/10.1590/S1413-24782006000300002

MENDES, E.G. Breve histórico da Educação Especial no Brasil. Revista Educación y Pedagogía, v. 22, n. 57, mai./ago., 2010.

NASCIMENTO, A.C.A.; OLIVEIRA, K. B.; MARINHO, M. F. B. Educação Inclusiva no Contexto Amazônico: formação de professores. Manaus: EDUA, 2007. 
OLIVEIRA. K.B. Educação Inclusiva e formação de professores no Alto Juruá: 133f. Dissertação (Mestrado em Educação) - Faculdade de Educação, Universidade Federal do Amazonas, Manaus, AM, 2007.

OMOTE, S. Normalização, integração, inclusão... Ponto de vista: revista de educação e processos inclusivos. Florianópolis, v.1, n.1, jul./dez., 1999.

ONGS BRASIL. ONGs em Manaus. Disponível em: http://www.ongsbrasil.com.br/default.asp. Acesso em: jan. 2017.

PESSOTTI, I. Deficiência mental: da superstição à ciência. São Paulo: T. A. Queiroz Editor, EDUSP, 1984.

RECH, T.L. A emergência da inclusão escolar no Governo FHC: movimentos que tornaram uma "verdade" que permanece. 2010. 183f. Dissertação (Mestrado em Educação) - Programa de PósGraduação em Educação, Universidade do Vale dos Rios dos Sinos, São Leopoldo, 2010.

SANTOS, J.O.L. et al. Atendimento Educacional Especializado: Reflexões sobre a Demanda de Alunos Matriculados e a Oferta de Salas de Recursos Multifuncionais na Rede Municipal de Manaus-AM. Revista Brasileira de Educação Especial, Marília, v.23, n.3, p.409-422, 2017. https://doi.org/10.1590/s1413-65382317000300007

SANTOS, L.M. A política pública de educação do município de Manaus: o atendimento educacional especializado na organização escolar. 2011. 209f. Dissertação (Mestrado em Educação) - Faculdade de Educação, Universidade Federal do Amazonas, Manaus, 2011.

SANTOS, L.M. As percepções dos usuários e usuárias da classe especial sobre esse serviço educacional. 102f. Dissertação (Mestrado em Educação) - Universidade Federal do Amazonas, Manaus, 1998.

SEMED. Secretaria Municipal de Educação: nossa história. Disponível em: http://semed.manaus.am.gov.br/nossa-historia/. Acesso em: 13 jun. 2017.

SEPED. Secretaria de Estado dos Direitos das Pessoas com Deficiência. 2015. Disponível em: http://www.amazonas.am.gov.br/entidade/secretaria-de-estado-dos-direitos-da-pessoa-comdeficiencia-seped/. Acesso em: jan. 2015.

VINENTE, S. Política e organização pedagógica do serviço de Atendimento Educacional Especializado em Manaus. 2017. 176f. Dissertação (Mestrado em Educação Especial) Centro de Educação e Ciências Humanas, Universidade Federal de São Carlos, São Carlos, 2017. https://doi.org/10.21723/riaee.v12.n1.8202.

VINENTE, S.; OLIVEIRA, S.S.B. Implementação do Atendimento Educacional Especializado e a formação de gestores na capital amazonense. Revista Ibero-Americana de Estudos em Educação, v.12, n.1, p.507-528, 2017.

VINENTE, S.; MATOS, M. A. S. M. O PPGE/UFAM e a produção do conhecimento científico em educação especial. In: CONGRESSO BRASILEIRO DE EDUCACÃO ESPECIAL, 6., São Carlos, Anais...São Carlos: EDUFSCar, 2014. Disponível em: <http://proceedings.galoa.com.br/cbee/trabalhos/o_ppgeufam_e_a_producao_do_conhecimen to_cientifico_em_educacao_especial>.Acesso em: dez. 2015. 